\title{
Impact of Socio-Economic and Demographic Characteristics of Chronic Obstructive Pulmonary Disease Patients on Hospital Application
}

\author{
${ }^{1}$ Hakan Celikhisar ${ }^{*}{ }^{2}$ Gulay Dasdemir Ilkhan \\ Department of Chest Deseases, İzmir Metropolitan Municipality Hospital, İzmir 35110, Turkey
}

Department of Chest Diseases, Okmeydanı Training and Research Hospital, Istanbul 34384, Turkey

\begin{abstract}
Several Objectives: Carrying out the social activities without any setback and minimizing hospital applications are among the leading approaches of our day towards COPD Patients. This is of special importance for minimizing both labor loss and financial losses. The purpose of our study was to evaluate whether the socioeconomic and demographic characteristics of COPD patients have an impact on emergency and hospital application, hospitalization and duration of hospitalization.

Method: The prospective study was carried out during March 2019 and September 2019 including 78 female and 147 male COPD patients with ages varying between 45 and 82 making up a total of 225 patients who applied to the pulmonary diseases polyclinic and emergency services of our hospital and who were hospitalized at the clinic for follow up. A survey comprised of 20 questions was applied on all patients. Evaluations were carried out for whether our cases are smokers or not, their education status, living environment, medication use, healthcare conveniences at their homes (oxygen cylinder-concentrator and/or nebulizer) as well as their hospital applications.
\end{abstract}

Results: Of the patients, $78(34.7 \%)$ were female, $147(65.3 \%)$ were male with an age average of $65.8+9.7$ (41-84). The ratio among our patients of those who applied to the hospital more than 10 times during the past year was $18.7 \%$. Of our patients, $12 \%$ applied at least 5 times whereas 52 did not apply to the emergency. Of all our cases, $24 \%$ have been hospitalized. The average hospitalization duration of our cases was $(23.4+19.7)$ days.

Conclusion: While the hospital application and hospitalization of patients with chronic obstructive pulmonary disease are affected by whether they are smokers or not, their education level, economic state, living environment, regular medication use; having healthcare conveniences at their homes does not have an impact on their hospital applications. The socioeconomic and demographic characteristics of patients with chronic obstructive pulmonary disease are effective on the prognosis of their disease and their hospital applications. Hence, the awareness of COPD patients should be increased with regard to creating an ideal living environment and they should receive training and support regarding the procurement and use of the required devices.

Keywords: Global COPD, exacerbation, socioeconomic and demographic characteristics

\section{Introduction}

Chronic obstructive pulmonary disease (COPD) is a progressive disease with adverse impacts on the functional capacity and psychological structure of the patients. A series of problems emerge that aggravate the daily lives of individuals such as fatigue, loss of labor, emotional changes, sleep disorder, mental and social restriction, nutritional disorder (1). Carrying out the social activities without any setback and minimizing hospital applications are among the leading approaches of our day towards chronic patients. Hence, various medical amenities are provided to ensure the continuity of treatment as well as to ensure that patients can lead better lives outside the hospital. The status of COPD patients at the time of hospitalization and the medical amenities provided during this period of time have an impact on the prognosis of the disease 
as well as their frequency of application to the hospital (2). Recently, it is considered that informing COPD patients about their disease, providing medical equipment they can use at home by themselves and teaching respiratory exercises will lead to significant improvements in their qualities of life. Hence, this approach has gained importance with increasing number of related studies (3). On the other hand, it is known that patients who are not under sufficient follow up and treatment apply to hospitals frequently due to progression of the disease or acute attacks (4).

In the present study, the personal characteristics of COPD patients, the qualities of their living environments outside the hospital, their monthly income levels, presence of nebulizer, oxygen cylinder, oxygen concentrator at their homes were determined and the impacts of these characteristics on the prognosis of the disease and hospitalization were examined.

\section{Materials and Method}

The study was carried out during March 2019 and September 2019 including 78 female and 147 male COPD patients with ages varying between 45 and 82 making up a total of 225 patients who applied to the pulmonary diseases polyclinic and emergency services of our hospital and who were hospitalized at the clinic for follow up. The age average of the cases was 65.8 \pm 9.7 . The survey assessment forms comprised of 20 questions for determining the age, gender, disease duration, whether our cases are smokers or not, their education status, economic status, living environment, medication use, accompanying diseases, healthcare conveniences at their homes (oxygen cylinder-concentrator and/or nebulizer) as well as their frequencies of hospitalization and hospital application were filled out either by the patient or by the mediation of the doctors if the patient is illiterate. Applications to the hospital for control purposes or for routine medication prescriptions were not included within the scope of the study.

\section{Statistical analysis}

NCSS (Number Cruncher Statistical System) 2007 (Kaysville, Utah, USA) was used for statistical analysis. Descriptive statistical methods (frequency, percentage) were used to evaluate the study data. Pearson chisquare test and Fisher-Freeman-Halton exact test were used to compare the qualitative data. The characteristics of the patients and hospitalization-admission relationships were determined by correlation and student-t test. Statistical significance was accepted as $\mathrm{p}<0.05$.

\section{Results}

Of our cases, $78(34.7 \%)$ were female, $147(65.3 \%)$ were male patients with an age average of $65.8 \pm 9.7$ (41-84). Thirty nine (17.3\%) of our patients were smokers. Six the 78 female cases $(7.6 \%)$ and 33 of the 147 male cases $(22.4 \%$ ) were smoker patients. Smoking packs per year was $38,8 \pm 14,0$. Whereas $38.7 \%$ of our non-smoker patients were subject to cigarette smoke at their place of residence. The number of smoker female patients who quit was $60(76.9 \%)$ and $12(15.3 \%)$ female patients have never smoked. Of our male cases $99(67.3 \%)$ have smoked and quit afterwards, whereas 14 have never smoked. Individuals graduated from high school and university were in the higher education group in our study; whereas those graduated from primary school, individuals that are literate and illiterate were included in the lower education level group. The education levels of our cases were as such; $9.3 \%$ illiterate, $4.0 \%$ literate, $22.7 \%$ primary school, 46. \% high school and $17.3 \%$ university graduates. Of our patients 162 (72\%) were married, 36 (16 $\%)$ were widowers, $9(4 \%)$ have never married. When the occupational states were examined, it was determined that 203 cases $(90.66 \%)$ are not working actively. It was observed when the monthly income levels were examined that 15 patients $(6.7 \%)$ have an income level of 150 dollars and less, $9(4 \%)$ have an income level of 150-250 dollars, 39 (17.3\%) have an income level of 250-500 dollars, $96(42.7 \%)$ have an income level of 500-750 dollars, $66(29.3 \%)$ have an income level of 750 dollars and more. Monthly income level classification was determined in accordance with the 2019 income and living conditions study by the Turkish Statistics Institute.

Of our patients, 189 (84\%) were living in their own homes (27 were private residences, 54 were apartment flats), $30(13.3 \%)$ were living in rent (9 private residences, 21 ' apartment flats). Of those living in apartment flats, $9(5 \%)$ were living in the ground floor, $18(10 \%)$ were living in the entrance floor, $27(15 \%)$ were living in the attic floor, $132(74 \%)$ were living in middle floors. Three $(1.3 \%)$ of our cases were living in a nursing home for seniors, $3(1.3 \%)$ were living with their children. The size distributions of the houses the live in were as such: $6.7 \%$ living room +1 room, $29.3 \%$ living room +2 rooms, $61.3 \%$ living room +3 rooms, 
$1.4 \%$ living room+4 rooms. For heating their homes, $69.3 \%$ were using radiator, 30.7' were using stove. Regular medication use ratio was about $84.0 \%$ on average.

It was observed when the health amenities of the patients were examined that $52 \%$ had nebulizer device, $14.7 \%$ had oxygen cylinder and that $6.7 \%$ had oxygen concentrator. The ratio of our patients who applied to the hospital for more than 10 times for complaints within the last year was $18.7 \%$. Of our patients, $12 \%$ applied to the hospital at least 5 times, while $52 \%$ did not apply to the emergency. Of all our cases, $24 \%$ have been admitted to the hospital. Average hospitalization duration for our patients treated at the hospital was determined as $(23.4 \pm 19.7)$ days.

Factors that affect the hospital-emergency application and admissions of our cases are presented in Table 1.

Table 1: Factors affecting hospital application and admission

\begin{tabular}{|l|c|c|c|c|}
\hline \multicolumn{1}{|c|}{$\begin{array}{c}\text { Hospital } \\
\text { application } \\
\text { frequency }\end{array}$} & $\begin{array}{c}\text { Emergency } \\
\text { application }\end{array}$ & $\begin{array}{c}\text { Number of } \\
\text { admissions }\end{array}$ & $\begin{array}{c}\text { Hospitalization } \\
\text { duration }\end{array}$ \\
\hline Age & $\mathrm{p}=0.09$ & $\mathrm{p}=0.10$ & $\mathrm{p}=0.15$ & $\mathrm{p}=0,24$ \\
\hline Gender & $\mathrm{p}=0.08$ & $\mathrm{p}=0.15$ & $\mathrm{p}=0.20$ & $\mathrm{p}=0.10$ \\
\hline Education & $\mathrm{p}=0.002$ & $\mathrm{p}=0.20$ & $\mathrm{p}=0.05$ & $\mathrm{p}=0.04$ \\
\hline Smoking & $\mathrm{p}=0.04$ & $\mathrm{p}=0.10$ & $\mathrm{p}=0.08$ & $\mathrm{p}=0.09$ \\
\hline Passive smoking & $\mathrm{p}=0.05$ & $\mathrm{p}=0.15$ & $\mathrm{p}>0.25$ & $\mathrm{p}=0.10$ \\
\hline Marital status & $\mathrm{p}=0.20$ & $\mathrm{p}=0.10$ & $\mathrm{p}>0.08$ & $\mathrm{p}=0.20$ \\
\hline $\begin{array}{l}\text { Number of those } \\
\text { living at home }\end{array}$ & $\mathrm{p}=0.09$ & $\mathrm{p}=0.04$ & $\mathrm{p}=0.15$ & $\mathrm{p}=0.10$ \\
\hline $\begin{array}{l}\text { Monthly income } \\
\text { level }\end{array}$ & $\mathrm{p}=0.0001$ & $\mathrm{p}=0.0001$ & $\mathrm{p}=0.0001$ & $\mathrm{p}=0.20$ \\
\hline Living in rent & $\mathrm{p}=0.08$ & $\mathrm{p}=0.15$ & $\mathrm{p}=0.15$ & $\mathrm{p}=0.15$ \\
\hline Home type & $\mathrm{p}=0.10$ & $\mathrm{p}=0.09$ & $\mathrm{p}=0.10$ & $\mathrm{p}=0.08$ \\
\hline Home size & $\mathrm{p}=0.10$ & $\mathrm{p}=0.04$ & $\mathrm{p}=0.04$ & $\mathrm{p}=0.10$ \\
\hline Heating & $\mathrm{p}=0.001$ & $\mathrm{p}=0.15$ & $\mathrm{p}=0.09$ & $\mathrm{p}=0.002$ \\
\hline Duration of disease & $\mathrm{p}=0.15$ & $\mathrm{p}=0.08$ & $\mathrm{p}=0.10$ & $\mathrm{p}=0.04$ \\
\hline $\begin{array}{l}\text { Regular } \\
\text { medication use }\end{array}$ & $\mathrm{p}=0.09$ & $\mathrm{p}=0.20$ & $\mathrm{p}=0.02$ & $\mathrm{p}=0.15$ \\
\hline Having medical \\
device
\end{tabular}

It was determined among our cases that those who smoke less, who live in stove heated homes, who have lower monthly income levels, who use their medications regularly and who have medical device at their homes applied to the hospital more frequently. This is indicated in Table 2. It was also determined that those living alone, those with low monthly income levels, those with medical equipment and those who do not use their medications regularly apply to the emergency more frequently (Table 3). When their hospital admission states were examined, it was observed that those with lower monthly income, those living in stove heated homes, those living in small homes and those who have medical amenities are admitted to the hospital more frequently (Table 4). Patients with lower education level, those living in stove heated homes and those with shorter disease duration were hospitalized for longer periods of time (Table 5). 
Table 2: Factors affecting hospital application frequency

\begin{tabular}{|l|l|l|}
\hline Factors & More frequent application & Less frequent application \\
\hline Education Level & Low & High \\
\hline Monthly income level & Low & High \\
\hline Heating & Stove heating & Radiator heating \\
\hline Regular medication use & Regular & Irregular \\
\hline Having medical equipment & Has & Does not have \\
\hline
\end{tabular}

Table 3: Factors affecting polyclinic application frequency

\begin{tabular}{|l|l|l|}
\hline Factors & More frequent application & Less frequent application \\
\hline $\begin{array}{l}\text { Number of individuals living } \\
\text { in their homes }\end{array}$ & Lives alone & Is not alone \\
\hline Monthly income & Low & High \\
\hline Size of the home & Small & Large \\
\hline Regular medication use & Irregular & Regular \\
\hline Having medical equipment & Has & Does not have \\
\hline
\end{tabular}

Table 4: Factors affecting number of hospital admissions

\begin{tabular}{|l|l|l|}
\hline Factors & More frequent admission & Less frequent admission \\
\hline Monthly income level & Low & High \\
\hline Size of the home & Small & Large \\
\hline Home type & Private residence & Apartment flat \\
\hline Heating & Stove heating & Radiator heating \\
\hline Having medical equipment & Has & Does not have \\
\hline
\end{tabular}

Table 5: Factors affecting duration of hospitalization

\begin{tabular}{|l|l|l|}
\hline Variable & Longer period & Shorter period \\
\hline Education Level & Low & High \\
\hline Disease duration & Short $(<10$ years $)$ & Long $(\geq 10$ years $)$ \\
\hline Heating & Stove heating & Radiator heating \\
\hline
\end{tabular}

\section{Discussion}

Chronic obstructive pulmonary disease (COPD) is a chronic, progressive disease characterized by decrease in lung capacity and increase in airway resistance (5). Even though COPD is considered as a reversible and treatable disease with its characteristic features related with pulmonary functions, it is a disease with high rates of mortality and morbidity in all societies that progresses until acute respiratory failure in progressive cases (6).

COPD related deaths are ranked high up in the world among reasons of death and hence studies are ongoing on the reasons and risk factors related with the disease (7). In addition to the characteristics of the disease, social conditions along with treatment compliance, socio-economic characteristics are also important in the course of chronic diseases. Suggestions and efforts for improving these will have a positive impact on the course of the disease as well as treatment response (8).

COPD generally develops in advanced age group due to smoking (9). Age average was determined in our study as $65.8 \pm 9.7$. COPD is observed more frequently in men than in women since they are subject to predisposing factors more. Female/male ratio in the present study was determined as 1/2 approximately.

The ratio of female / male COPD patients in the United States of America is close to 1/1. We put forth that the difference is due to the fact that the habit of smoking is less prevalent among the female population of 
our country which is one of the important factors of COPD. Smoking habit was observed in our cases as $17.3 \%$. This ratio was about $7.7 \%$ for female cases. Moreover, $38.7 \%$ of our non-smoker cases were passive smokers. Whereas age and gender did not have an impact on hospital application and admission, we observed that heavy smokers for long periods of time applied to the hospital less. We are of the opinion that smoking addicts apply to the hospitals less for fear that the doctors will prohibit smoking.

It was observed when the education levels of our patients were examined that $76 \%$ have an education level of secondary school and above, whereas the ratio of illiterate patients was determined as $9.3 \%$. It was observed that patients with lower education level applied to the hospital more frequently and were admitted for longer periods of time. Another study put forth that individuals ignore their health more frequently with increasing education level (10). The fact that application to the hospital was observed to be less in our COPD cases with increasing education level can be explained by the fact that educated patients use their medication more regularly and more accurately in a conscious manner.

Asthma as well as psycho-social factors is of significant importance for COPD. It was determined that 162 $(72.0 \%)$ of our patients are married and that $57(25.33 \%)$ live alone. Marty et al. reported in a recent study that $45 \%$ of COPD patients live alone (11). We observed that patients living alone applied to the hospital more frequently. We are of the opinion that application to the hospital increases in COPD patients living alone due to fear of death and that both acute attacks and psycho-social factors are observed more frequently in these patients due to insufficient care.

COPD patients generally have a progressive hypoxemia. Hypoxemia results in cell damage and oxygen device is required for patients based on their blood gas results. It was determined that $21.4 \%$ of our patients use oxygen cylinder or concentrator at their homes. Moreover, it was also put forth that $52.0 \%$ of our patients have a nebulizer at home. Chen et al. reported in their studies that the ratio of using medication with nebulizer is about $45 \%$ (12). A statistically significant difference could not be determined between the hospital applications of patients with and without oxygen cylinder at their homes. Indeed, it was observed that patients with oxygen cylinder at their homes apply to the emergency more frequently. This can be considered to be due to the disease severity of the patients. The fact that patients with healthcare amenities at their homes frequently apply to the hospital and are admitted leads us to think that they cannot make sufficient use of these devices. It has become especially apparent that our patients need more knowledge and training in these issues.

Majority of the patients in our study indicated that they use medications regularly. However, there was no statistically significant connection between regular medication use and the education levels of the patients. It has been reported in a study by Cushen et al. that $45.5 \%$ of the patients do not use their medications regularly and that medication use and education level are inversely related (13). It was determined in the present study that patients who use medications regularly apply to the hospital more frequently but less to the emergency. It can be accepted as an expected outcome that these patients apply to the emergency less because they are more aware of their disease and are followed up better.

Even though the monthly income levels of our cases were quite low, majority were living in their own homes. Only 3 of our cases were living at a nursing home for seniors and 3 of our cases were living with their children. Majority of our patients were living in an apartment and in flats with central heating. Türker et al. put forth that $59 \%$ of the COPD patients live in apartments, $33 \%$ live in shanty houses, $6 \%$ live in the basement floor and that $2 \%$ live in the attic floor with 88 of the homes heated with a heating stove. It was observed that the socio-economic states of our cases were quite good in comparison with the country in general. It was put forth that patients with low monthly income apply to the hospital and emergency polyclinic more frequently and were also admitted more frequently. The prevalence of the disease increases among individuals with low socio-economic levels (14). Hence, the relations between economic state and the disease were determined to be as expected.

It is known that the disease will progress further in patients who are not followed up properly and who are not undergoing any treatment or that they will apply to the doctors or hospitals much more frequently due to acute attacks. It was determined in the present study that our patients applied to the hospital 6 times on average in one year due to complaints and that they applied to our polyclinic at least about 1-2 times annually for acute attacks. Sprooten et al. determined in their study that the need for hospital treatment 
increases in male COPD patients after the age of 50 (15). Another study reported the statistically significant relationship between low education level and income and hospital admission indicating that social and economic factors are effective in COPD development at early stages of one's life (16). Age and gender of our patients did not have any impact on the hospital application-admission of our patients. However, it was observed that socio-economic factors have a statistically significant impact.

In conclusion, living environments of the patients and the medical devices they own are effective on the course of the disease as well as hospital applications. Thus, patients should be informed about ideal living conditions for COPD and they should be encouraged to create the ideal environment for themselves. We are of the opinion that it is required to inform our COPD patients about their disease in addition to the procurement and use of medical devices which play an important part of treatment outside the hospital.

\section{References}

[1.] Nakken N, Janssen DJ, Van Den Bogaart EH, Van Vliet M, De Vries GJ, Bootsma GP, et al. Patient versus proxy-reported problematic activities of daily life in patients with COPD. 2017;22(2):307-14.

[2.] Van Helvoort HA, Willems LM, Dekhuijzen PR, Van Hees HW, Heijdra YFJNpcrm. Respiratory constraints during activities in daily life and the impact on health status in patients with early-stage COPD: a cross-sectional study. 2016;26:16054.

[3.] Tabberer M, Lomas DA, Birk R, Brealey N, Zhu C-Q, Pascoe S, et al. Once-daily triple therapy in patients with COPD: patient-reported symptoms and quality of life. 2018;35(1):56-71.

[4.] Moy ML, Collins RJ, Martinez CH, Kadri R, Roman P, Holleman RG, et al. An internet-mediated pedometer-based program improves health-related quality-of-life domains and daily step counts in COPD. 2015;148(1):128-37.

[5.] Celli BR, MacNee W, Agusti A, Anzueto A, Berg B, Buist AS, et al. Standards for the diagnosis and treatment of patients with COPD: a summary of the ATS/ERS position paper. 2004;23(6):93246.

[6.] Mannino DM, Buist ASJTL. Global burden of COPD: risk factors, prevalence, and future trends. 2007;370(9589):765-73.

[7.] Rosenberg SR, Kalhan R, Mannino DM, editors. Epidemiology of chronic obstructive pulmonary disease: prevalence, morbidity, mortality, and risk factors. Semin Respir Crit Care Med; 2015: Thieme Medical Publishers.

[8.] Hemnes A, Ventetuolo C, Manaker S, Noone J, Howden R, Classi P, et al. The Economic Burden of Pulmonary Hypertension Among Patients with Chronic Obstructive Pulmonary Disease and Interstitial Lung Disease. D93 PAYING FOR CARE IN PULMONARY DISEASES: American Thoracic Society; 2019. p. A7035-A.

[9.] Quaderi S, Hurst JJGh, epidemiology, genomics. The unmet global burden of COPD. 2018;3.

[10.] Lin M, Chen Y, McDowell IJCrd. Increased risk of depression in COPD patients with higher education and income. 2005;2(1):13-9.

[11.] Marty P, Benzo R. Loneliness and Emergency Department Visits in Chronic Obstructive Pulmonary Disease. D102 OPTIMIZING OUTCOMES IN COPD: American Thoracic Society; 2019. p. A7121-A.

[12.] Chen Z. Impact of Social Support on Patients with Chronic Obstructive Pulmonary Disease: University of Washington; 2017.

[13.] Cushen B, Sulaiman I, Greene G, MacHale E, Mokoka M, Reilly RB, et al. The clinical impact of different adherence behaviors in patients with severe chronic obstructive pulmonary disease. 2018;197(12):1630-3. 
[14.] Fernández-García S, Represas-Represas C, Ruano-Raviña A, Mosteiro-Añón M, Mouronte-Roibas C, Fernández-Villar AJAdb. Social Profile of Patients Admitted for COPD Exacerbations. A Gender Analysis. 2019.

[15.] Sprooten RT, Rohde GG, Lawyer G, Leijte WT, Wouters EF, Franssen FMJR. Risk stratification for short-term mortality at hospital admission for acute exacerbations of COPD. 2019.

[16.] Fazekas AS, Aboulghaith M, Kriz RC, Urban M, Breyer M-K, Breyer-Kohansal R, et al. Longterm outcomes after acute hypercapnic COPD exacerbation. 2018;130(19-20):561-8. 